Polymer Journal, Vol. 38, No. 9, pp. 949-955 (2006)

(C) 2006 The Society of Polymer Science, Japan

\title{
A Novel Carbon Black/Polydimethylsiloxane Composite Membrane with High Flux for the Separation of Ethanol from Water by Pervaporation
}

\author{
Shengpeng SHI, ${ }^{1,2}$ Zhongjie Du, ${ }^{1}$ Hong Ye, ${ }^{1}$ Chen ZHANG, ${ }^{1}$ and Hangquan $\mathrm{LI}^{1, \dagger}$ \\ ${ }^{1}$ The Key Laboratory of Beijing City on Preparation and Processing of Novel Polymer Materials, \\ Beijing University of Chemical Technology, Beijing 100029, China \\ ${ }^{2}$ SINOPEC Beijing Research Institute of Chemical Industry, Beijing 100013, China
}

(Received February 24, 2006; Accepted June 14, 2006; Published August 4, 2006)

\begin{abstract}
A novel inorganic/organic composite membrane was prepared through introducing carbon black into polydimethylsiloxane (PDMS) membrane. Carbon black was treated with various measures, including extraction, methylolation, and high-temperature calcinations in order to tailor the nature of the surface. The effects of surface treatment, carbon black loading, particle size, and temperature on the pervaporation performance in the extraction of ethanol from ethanol/water mixtures were explored. In certain ranges of composition, the flux was remarkably increased without reducing the selectivity. [doi:10.1295/polymj.PJ2005238]

KEY WORDS Carbon Black / Polydimethylsiloxane / Ethanol-permselective / Pervaporation / Composite Membrane /
\end{abstract}

In recent years, a great deal of attentions had been focused on the pervaporation to separate the azeotropic mixtures, close boiling point mixtures, isomers or heat-sensitive mixtures, which are difficult or impossible for conventional distillation methods. With the attractiveness of low energy consumption and easier process, water/ethanol separation constituted a wellknown example of pervaporation process in chemical industry. ${ }^{1-10}$ Especially there has been growing research interest in the pervaporation to recover ethanol from fermentation broths. ${ }^{1-14}$ Fermentation-derived ethanol represents one of the more important resources of renewable energy, while the amount of carbon dioxide released during production and combustion is equivalent to the amount of carbon dioxide absorbed by replanted biomass. ${ }^{15}$ Ethanol is also a cleaner fuel compared to fossil fuels, which often contain nitrogen and sulfur compounds and produce nitrogen and sulfur oxides during combustion. The use of fermentationderived ethanol also eases world's dependence on fossil energy and decreases emission of greenhouse gases. ${ }^{16}$

Silicone rubber has been the most widely used and studied material to perform ethanol extraction from fermentation broth. ${ }^{2-5,17,18}$ Polydimethylsiloxane (PDMS) is a typical example for the ethanol permselective membrane. A number of methods have been employed to chemically and/or physically modify the properties of PDMS membranes, in order to enhance separation performance. The physical ones involved the incorporation of an organophilic component such as a zeolite into PDMS membrane, ${ }^{19,20}$ and the chemical ones tried to tailor its performance to meet the requirements of the separation, ${ }^{21,22}$ while different types and physicochemical properties of zeolite brought the different pervaporation properties to us. ${ }^{23-25}$

As we known, the carbon black coacervate particle consists of lied graphite layer, on the surface of which some hydrogen, oxygen and sulfur form surface functional groups such as hydroxyl or carboxyl, and control chemical properties. ${ }^{26,27}$ The carbon black (CB) is almost a completely carbonaceous material just the same as backbones of most organic compounds, which should result in the hydrophobic nature and the selectivity for organic compounds over water. In this paper, we investigate pervaporation characteristics of the PDMS membrane compounded with the carbon black.

\section{EXPERIMENTAL}

\section{Materials}

Polydimethylsiloxane (PDMS) was purchased from Beijing Huaer Limited, China, carbon Black was from Tianjin Dolphin Rubber Group Limited, China, tetraethylorthosilicate (TEOS), sodium hydroxide, dibutyltin dilaurate, $n$-decane, cyclohexane, tetrahydrofuran, formaldehyde, ethanol, butanone, and acetone were obtained as analytical reagents from Beijing Chemical Reagents Co, China. Distilled and deionized water was used. Microporous Nylon-6 Membranes with an average pore size of $0.8 \mu \mathrm{m}$ were from Huada Liming Co, China and used as support membranes.

${ }^{\dagger}$ To whom correspondence should be addressed (Tel: +86-010-64445339, Fax: +86-010-64428804, E-mail: hli45@yahoo.com.cn). 
Table I. Characteristics of different carbon blacks without modification from manufacture

\begin{tabular}{cccc}
\hline Carbon black & $\begin{array}{c}\text { Particle size } \\
(\mathrm{nm})\end{array}$ & $\begin{array}{c}\text { DBP } \\
(\mathrm{mL} / 100 \mathrm{~g})\end{array}$ & $\begin{array}{c}\text { BET } \\
\left(\mathrm{m}^{2} / \mathrm{g}\right)\end{array}$ \\
\hline N110 & 18 & 113 & 143 \\
N330 & 29 & 102 & 81 \\
N660 & 68 & 90 & 34 \\
\hline
\end{tabular}

\section{Surface Treatment of Carbon Black}

The main properties of crude carbon black are listed in Table I.

The carbon black was treated in four ways:

I. The carbon black was dried at $120^{\circ} \mathrm{C}$ for $24 \mathrm{~h}$ in the vacuum oven.

II. The carbon black was extracted via Soxhlet extraction with toluene as an extractant under $\mathrm{N}_{2}$ atmosphere for $48 \mathrm{~h}$ to remove the crude oil on its surface.

III. $10 \mathrm{~g}$ of toluene-extracted carbon black was mixed with $100 \mathrm{~mL}$ methanol $(37 \mathrm{wt} \%)$ and $10 \mathrm{~mL}$ sodium hydroxide (20 wt \%), and stirred at $50^{\circ} \mathrm{C}$ for $5 \mathrm{~h}$. And the reaction was terminated by cooling to room temperature. Subsequently the carbon black was retrieved and washed with distilled water and dried in a vacuum.

IV. The carbon black was dried at $120^{\circ} \mathrm{C}$ for $24 \mathrm{~h}$ and extracted with toluene, subsequently calcined at $900^{\circ} \mathrm{C}$ for $1 \mathrm{~h}$ in a controlled inert atmosphere in which it was heated to the pyrolysis temperature at a specific heating rate for a sufficiently long thermal soak time.

Above treating methods will be denoted as M1, M2, $\mathrm{M} 3$, and M4, and the resulted carbon black as B1, B2, B3, and B4, respectively.

\section{Preparation of the Membrane}

PDMS was diluted with $n$-decane and mixed with crosslinker TEOS, catalyst dibutyltin dilaurate, and carbon black according to certain weight ratios. A microporous Nylon-6 film was laid smoothly on a glass sheet. The PDMS mixture was cast on over the surface of the microporous Nylon-6 film forming a thin skin layer, which was kept at ambient temperature for $5 \mathrm{~h}$ to complete the crosslinking and vacuum dried at $25^{\circ} \mathrm{C}$ for $24 \mathrm{~h}$. A composite membrane was thus obtained with a skin PDMS layer about $20 \mu \mathrm{m}$ in thickness.

\section{TG Measurements}

A NETZSCH STA 449C TG-DSC simultaneous analyzer was used to determine the weight loss behaviors of the carbon black during heating. The carbon black sample was heated to $1400{ }^{\circ} \mathrm{C}$ at a rate of $10^{\circ} \mathrm{C} / \mathrm{min}$. The experiments were carried out under dynamic inert air at a flowing rate of $20 \mathrm{~mL} / \mathrm{min}$.

\section{DMTA Measurements}

Dynamic mechanical measurement was carried out using American Rheometric Scientific DMTA-V thermal analysis system, with DMA mode between ambient and $300^{\circ} \mathrm{C}$, with a heating rate of $5^{\circ} \mathrm{C} / \mathrm{min}$ at a frequency of $1 \mathrm{~Hz}$ a under nitrogen atmosphere. The temperature/time scan in a one-point bending mode was chosen and the dimension of the specimen was $30 \times 5 \times 2 \mathrm{~mm}$. The storage modulus $\mathrm{E}^{\prime}$ and mechanical loss factor $(\tan \delta)$ were determined.

\section{Contact Angle Measurements}

The contact angles of carbon blacks/polydimethylsiloxane composite membranes for water were determined through static sessile-drop contact angle measurement technique, with a JJC-1 goniometer.

\section{Membrane Pervaporation}

The pervaporation apparatus was presented in Figure 1. A circular flat membrane was clamped into a sealed stainless steel test cell above a porous sintered metal support with a viton 'o' ring arrangement forming a leak free seal, giving a pervaporation area of $0.0007 \mathrm{~m}^{2}$. The cell containing the feed solution was placed under a stirrer and in a constant temperature water bath, with the feed being stirred at $500 \mathrm{rpm}$. The cell temperature was controlled and measured with a thermocouple and electronic temperature control system, accurate to $\pm 0.5^{\circ} \mathrm{C}$. A vacuum pump on the downstream side maintained a low pressure about $5 \pm 1 \mathrm{mmHg}$ between the cell and the cold trap.

The permeate was condensed and frozen within the cold trap, which was cooled with liquid nitrogen. Permeate was collected for a certain time period (generally $20 \mathrm{~min}$ ) and was subsequently weighted and analyzed, in order to determine flux and selectivity. The results of the first experiment for each new membrane disc were disregarded, because a new membrane was

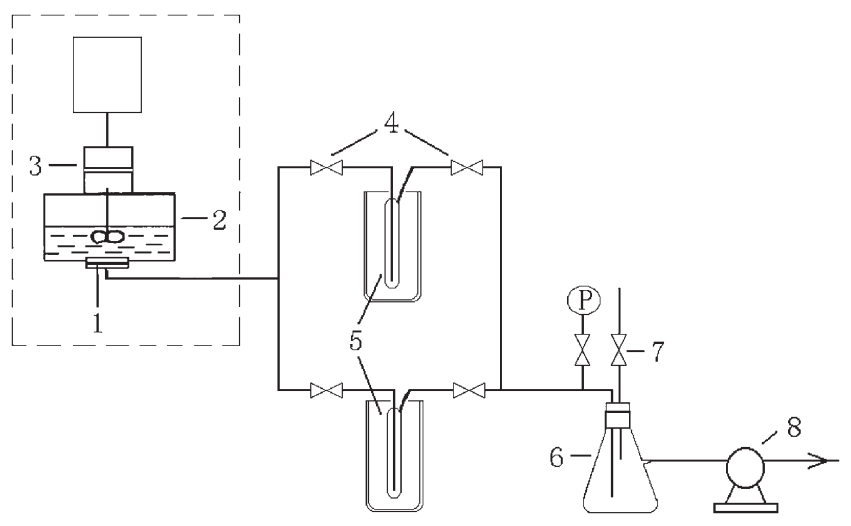

Figure 1. Schematic diagram of the pervaporation apparatus: (1) membrane; (2) feed reservoir; (3) mechanical stirrer; (4) switch valve; (5) collection trap; (6) safety trap; (7) switch valve; (8) vacuum pump. 


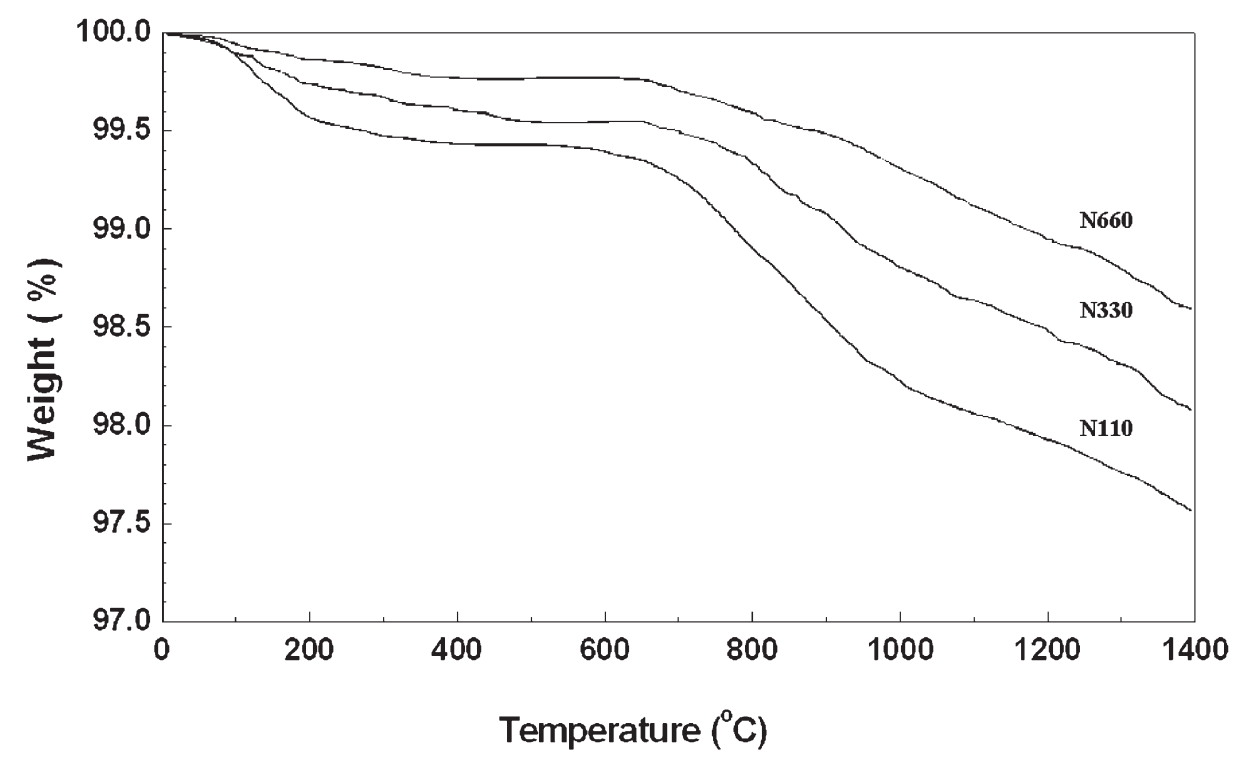

Figure 2. The TG curves of different carbon blacks in dynamic inert air at a heating rate of $10^{\circ} \mathrm{C} / \mathrm{min}$.

often found to undergo initial conditioning. Subsequent experiments were repeated until consecutive sets of results were closely similar. The results reported here are an average of five measurements.

\section{Calculation of Membrane Separation Parameters}

The pervaporation flux $\mathrm{J}$ (in $\mathrm{g} / \mathrm{m}^{2} \mathrm{hr}$ ) and the separation factor $\alpha$ were calculated using the expressions: $J=\frac{Q}{A \cdot t}$ and $\alpha=\frac{Y_{\mathrm{E}} / Y_{\mathrm{W}}}{X_{\mathrm{E}} / X_{\mathrm{W}}}$, where $\mathrm{Q}=$ weight $(\mathrm{g})$ of permeate, $\mathrm{t}=$ permeation time $(\mathrm{h}), \mathrm{A}=$ membrane area $\left(\mathrm{m}^{2}\right) ; X_{\mathrm{E}}$ and $X_{\mathrm{W}}$ represent the weight fractions of ethanol and water of the feed mixture, and $Y_{\mathrm{E}}$ and $Y_{\mathrm{W}}$ represent the weight fractions of ethanol and water of the permeate, respectively.

\section{RESULTS AND DISCUSSION}

As mentioned in the experimental section, the carbon black was treated with four methods. For the M1 method, only the hydroscopic water was removed from the surface of the carbon black, the crude oil remained. For M2, the crude oil on the surface was removed, however, the various water species were kept intact. For M3, after the oil was removed, hydroxymethyl groups were introduced onto the surface of the carbon black via the reaction between methanol and the terminal hydroxyl, thus the polarity of the surface was reduced.

The process of M4 treatment was illustrated with the TG curves in Figure 2. the hydroscopic moisture and the adsorbed water were volatilized from room temperature to $400^{\circ} \mathrm{C}$ while the volatile and some grafting component were removed at temperature from $200{ }^{\circ} \mathrm{C}$ to almost $1000^{\circ} \mathrm{C}$. And the carbon black was pyrolyzed above $1000^{\circ} \mathrm{C} .{ }^{28}$
Table II. Influence of filling carbon black in the composite membrane on the contact angles $\left(^{\circ}\right)$

\begin{tabular}{ccccc}
\hline Method & N110 & N330 & N660 & PDMS \\
\hline M1 & 115.6 & 111.5 & 106.7 & \\
M2 & 121.9 & 113.7 & 107.1 & 105.4 \\
M3 & 117.6 & 112.3 & 106.8 & \\
M4 & 122.5 & 114.6 & 107.9 & \\
\hline
\end{tabular}

The treatments resulted in different surface nature of the carbon black leading to different affinity to the silicon rubber matrix. For the above reasons, the order of surface polarity should be B2 $>\mathrm{B} 1>\mathrm{B} 3>$ $\mathrm{B} 4$, which was confirmed by the contact angles to water of the composite membranes in Table II.

The adhesion between the two components can also be correlated to the loss factor $(\tan \delta)$. The poorer the adhesion, the larger the $\tan \delta$. As shown in Figure 3, DMTA measurements provided an order of $\tan \delta$ as $\mathrm{B} 2>\mathrm{B} 1>\mathrm{B} 3>\mathrm{B} 4$, which was in consistent with that of the polarities of surface of carbon black.

It is interesting to notice that the flux of the membrane changed systematically with the surface polarity of the carbon black, when other conditions maintained constant, as shown in Table III, in which the rows 1, 2, 3, and 4 were based on carbon blacks B1, B2, $\mathrm{B} 3$, and B4, respectively. Table III indicated that the lower the surface polarity of the carbon black, the greater the flux of the membrane. One may concluded that the affinity between the carbon black and the silicon rubber played a major role in the flux.

A well-known mechanism of pervaporation can be described as solution-diffusion. ${ }^{29}$ The liquid feed penetrant molecules was first dissolved at the upstream surface of the membrane, subsequently diffused to 


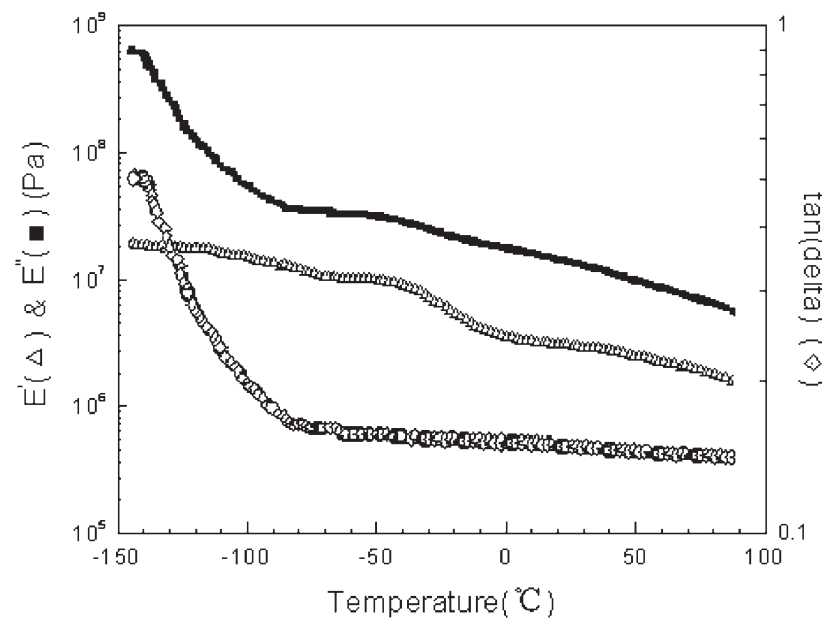

(a)

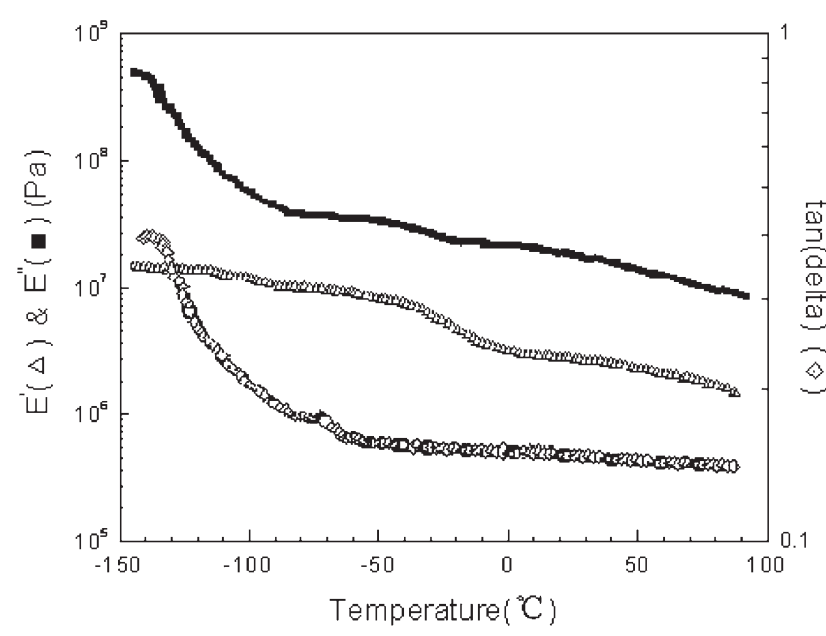

(b)

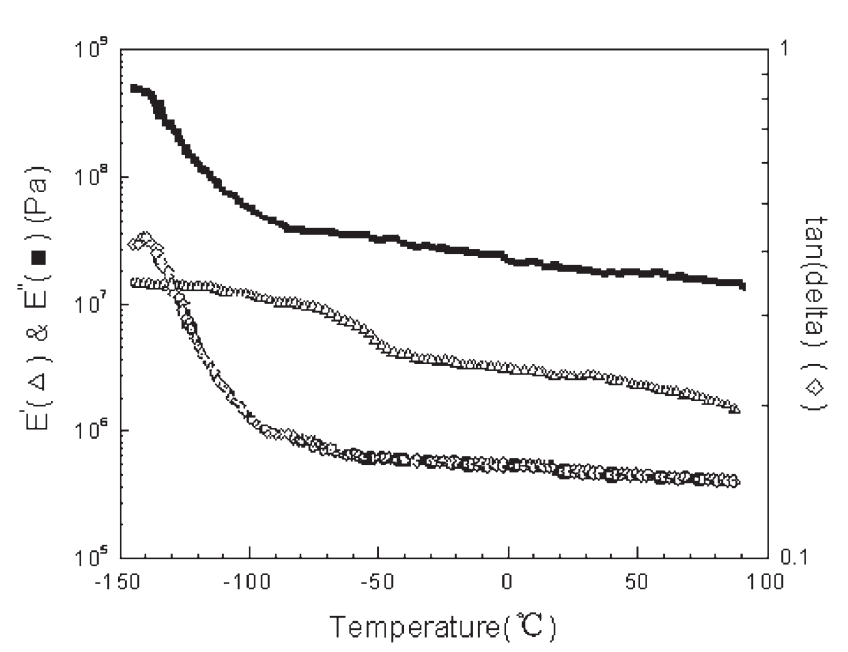

(c)

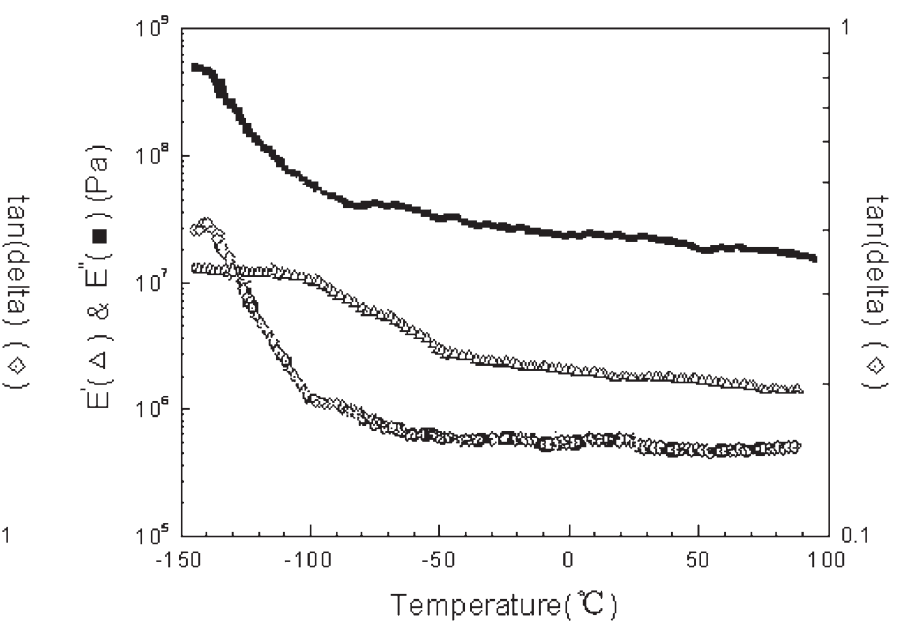

(d)

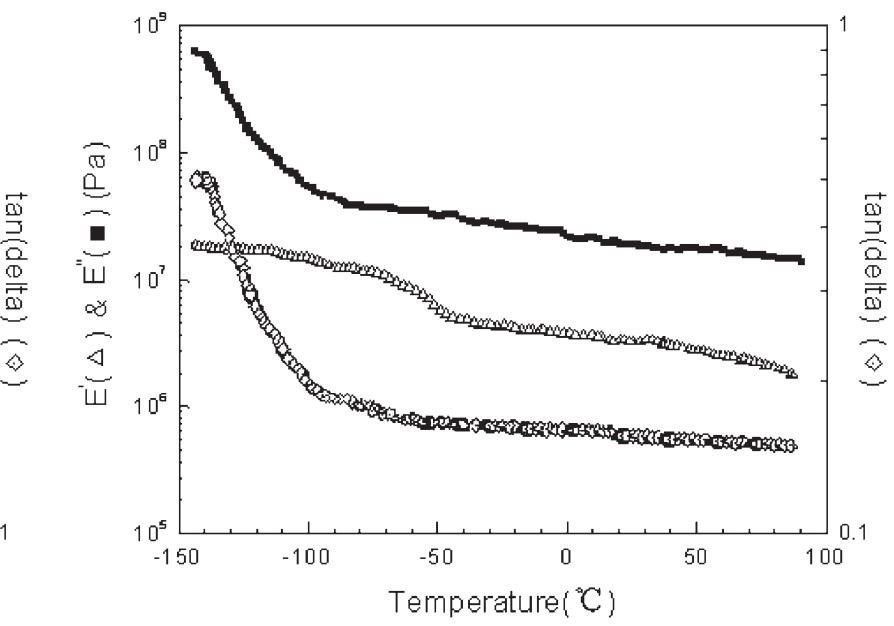

(e)

Figure 3. The DMTA curves of the composite membranes scanned at $10^{\circ} \mathrm{C} / \mathrm{min}$ in dynamic nitrogen atmosphere: (a) PDMS; (b) $\mathrm{B} 1_{(\mathrm{N} 110)} ;$; (c) $\mathrm{B} 2_{(\mathrm{N} 110)}$; (d) $\mathrm{B} 3_{(\mathrm{N} 110)}$; (e) $\mathrm{B} 4_{(\mathrm{N} 110)}$.

the downstream side, and finally desorbed off the membrane. The driving force of the permeation is the concentration gradient of permeates across the membrane, however, as showed in a previous work, ${ }^{30}$ the rate of diffusion was also controlled by the size and polarity of permeates.

In the present case, the size of ethanol molecules is larger than those of water, however, its polarity is closer to the membrane material. On the other hand, water molecules are unfavorable in polarity but small- 
Table III. Influence of filling carbon black in the composite membrane on the permeation rate $\mathrm{J}\left(\mathrm{g} \mathrm{m}^{-2} \mathrm{hr}^{-1}\right)$

\begin{tabular}{ccccc}
\hline Method & N110 & N330 & N660 & PDMS \\
\hline M1 & 160 & 151 & 130 & \\
M2 & 183 & 176 & 160 & 110 \\
M3 & 161 & 158 & 148 & \\
M4 & 233 & 234 & 169 & \\
\hline
\end{tabular}

Note: Ethanol content in feed mixture is $13.73 \mathrm{wt} \%$. Feed temperature is $30^{\circ} \mathrm{C}$.

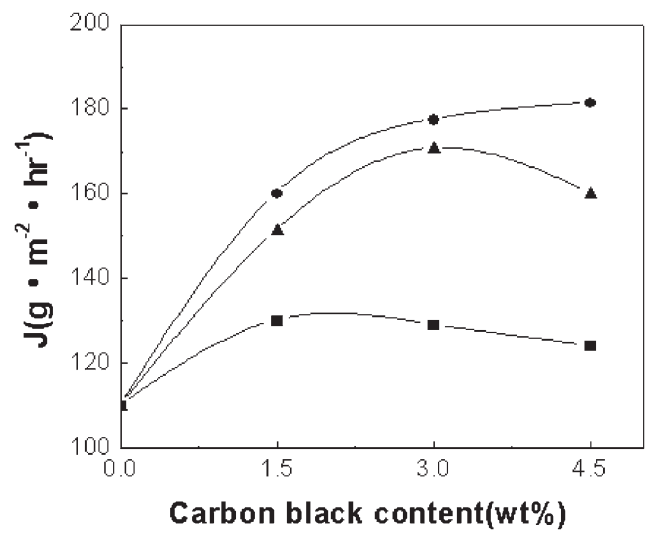

Figure 4. Influence of carbon black content in the composite membrane on permeation rate, $\bullet$ : membranes filled with N110; $\Delta$ : membranes filled with $\mathrm{N} 330$; $\boldsymbol{\square}$ : membranes filled with N660; ethanol content in feed mixture: $13.73 \mathrm{wt} \%$.

er in size. In a dense membrane, the pathway of diffusion was solely provided by the free volume among the molecular chains. The average inter-chain distance among the amorphous flexible chains is $0.4-0.5 \mathrm{~nm}$ and the van der Waals radius of water and ethanol molecules are 0.26 and $0.52 \mathrm{~nm},{ }^{31-33}$ respectively. It would make more obstacles for ethanol than water. Via providing enlarged pathway, the diffusion of ethanol could be promoted. As seen in Table III, this was achieved through the introduction of carbon black into the rubber matrix. No matter how pretreated, there must be micro-voids between the rubber and carbon particles, because of the difference in chemical nature. Those micro-voids provided additional pathway for permeates and thus increased the flux. Of course, the poorer the affinity between rubber and carbon black, the larger the micro-voids, and the greater the flux that could be achieved.

Figure 4 shows the effect of the content of carbon black on the flux, it is obvious that the higher the content of carbon black, the greater the flux in certain ranges, although the degree of increase was dependent on the treatment method. As a result of the above mechanism, the carbon black introduced additional pathway for permeates and thus the permeation rate $\mathrm{J}$ was improved.

The permeation rate $\mathrm{J}$ was also affected by the par-
Table IV. Influence of filling carbon black in the composite membrane on the separation factor

\begin{tabular}{ccccc}
\hline Method & N110 & N330 & N660 & PDMS \\
\hline M1 & 8.9 & 9.0 & 9.0 & \\
M2 & 8.8 & 8.8 & 8.8 & 9.0 \\
M3 & 8.8 & 8.8 & 8.7 & \\
M4 & 8.8 & 8.9 & 8.9 & \\
\hline
\end{tabular}

Note: Ethanol content in feed mixture is $13.73 \mathrm{wt} \%$. Feed temperature is $30^{\circ} \mathrm{C}$.

Table V. Influence of carbon black content in the composite membrane on the separation factor

\begin{tabular}{ccccc}
\hline Carbon black content (wt \%) & 0 & $1.5 \%$ & $3.0 \%$ & $4.5 \%$ \\
\hline N110 & 9.0 & 8.9 & 9.0 & 8.9 \\
N330 & 9.0 & 9.0 & 8.9 & 8.9 \\
N660 & 9.0 & 9.0 & 8.9 & 8.9
\end{tabular}

Note: Ethanol content in feed mixture is $13.73 \mathrm{wt} \%$. Feed temperature is $30^{\circ} \mathrm{C}$.

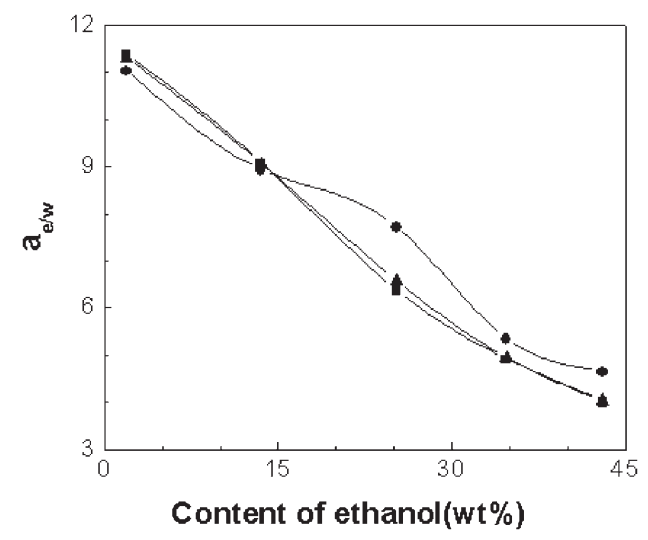

Figure 5. Influence of the ethanol content in feed mixture on the separation factor of composite membrane, $\bullet$ : membranes filled with $1.5 \mathrm{wt} \%$ N110; $\boldsymbol{\Lambda}$ : membranes filled with $1.5 \mathrm{wt} \%$ N330;

口: membranes filled with $1.5 \mathrm{wt} \%$ N660.

ticle size of the carbon black. Table II shows that at the same weight content, the smaller the average diameter of carbon black, and the greater the flux. The larger surface area of smaller particles should be responsible for this effect. In the vicinity of each particle of carbon black, micro-voids occurred. The more particles, the more micro-voids. As a result, the flux increased with decreasing particle size.

The common sense suggests that an increase in flux was inevitably accompanied by a decrease in selectivity. It is interesting to notice that in this work the selectivity was almost not affected by the introduction of carbon black (as shown in Tables IV and V). This could be easily explained as the hydrophobicity of the surface of carbon black. After proper treatment, the surface should as hydrophobic as the silicon rubber. However, as an inorganic material, it would not 


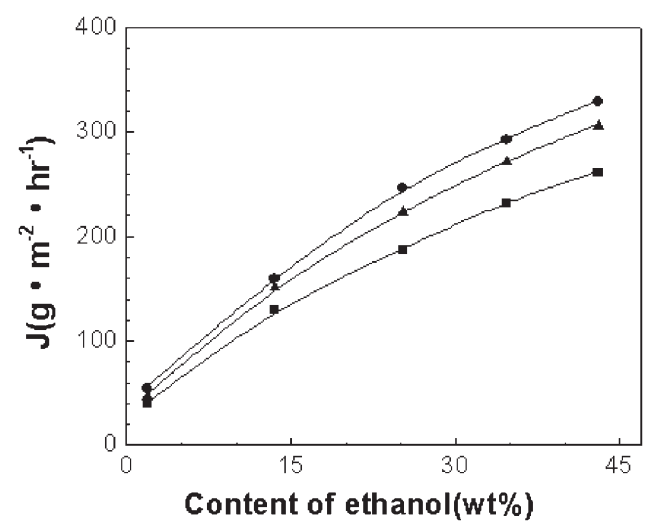

Figure 6. Influence of the ethanol content in feed mixture on the permeation rate of composite membrane, $\bullet$ : membranes filled with $1.5 \mathrm{wt} \% \mathrm{~N} 110 ; \boldsymbol{\Delta}$ : membranes filled with $1.5 \mathrm{wt} \%$ N330; membranes filled with $1.5 \mathrm{wt} \%$ N660.

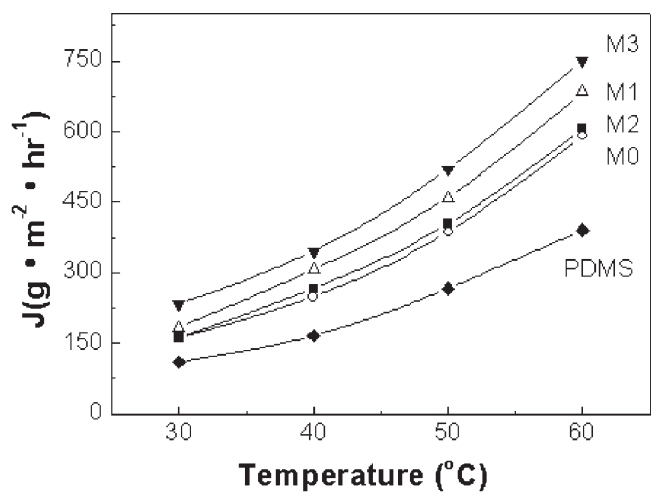

(a)

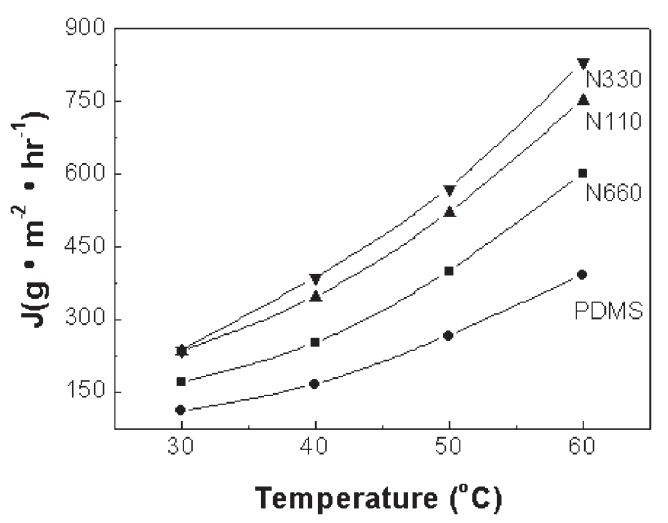

(b)

Figure 7. Influence of feed temperature on the permeation rate of composite membrane: the kind of carbon black used in (a) was N110 with different treatments, carbon blacks used in (b) was modified by M3 method.

promote the adsorption of ethanol molecules, as a result, the selectivity was not enhanced.

Figure 5 showed the relationship between the separation factor and the composition of the feed mixture. It is seen that the higher the volume ratio of ethanol in the feed, the poorer the selectivity, while the higher the flux as shown in Figure 6. This is normal in the

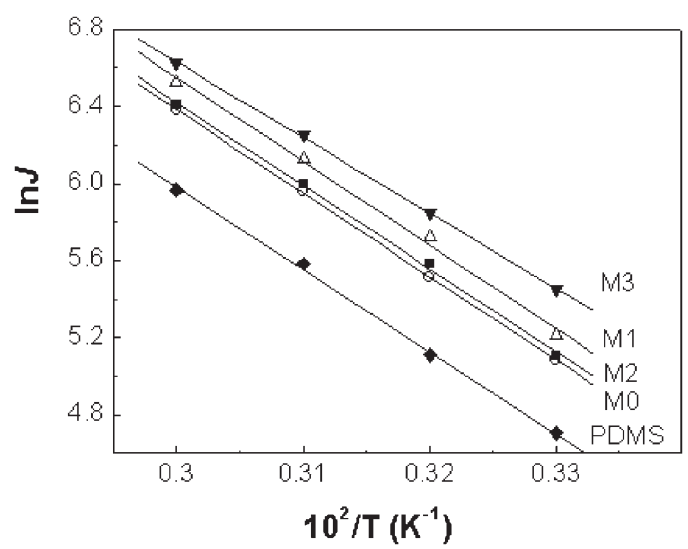

(a)

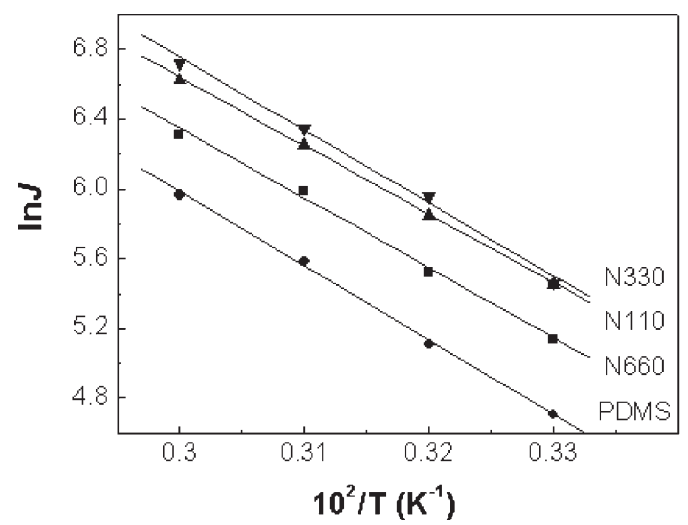

(b)

Figure 8. The relation between the natural logarithm of permeation rate and the inverse of feed temperature for composite membranes: the kind of carbon black used in (a) was N110 with different treatments, carbon blacks used in (b) was modified by M3 method.

process of separating ethanol from water, owing to the close of polarities of the two species. In spite of the inclusion of carbon black, whose surface was managed to be hydrophobic, the selectivity was not improved, which remained a difficulty in the ethanol separation from water.

Figures 7 and 8 illustrated the effect of temperature on the flux. The permeation rates markedly increased with the raising feed temperature. It is reasonably to assume the flux follows an Arrhenius behavior: $J=J_{0} e^{-\frac{\Delta E_{a}}{R T}}$. Figure 8 showed that the natural logarithm of permeation rate kept a good linear relationship with the inverse of feed temperature. The apparent permeation activation energies $\left(E_{\mathrm{a}}\right)$ determined from regression are all positive, as listed in Table VI. There are three factors that contribute to the positive apparent permeation activation energy: (i) increase in the solubility with temperature; (ii) increase in the diffusivity with temperature; and (iii) increase in the pathway for permeates. However, as discussed above, the selectivity was not affected much by temperature in Table VII. 
Table VI. Apparent permeation activation energy of the mixture in different composite membranes

\begin{tabular}{cccccccc}
\hline & PDMS & B1(N110) & B2(N110) & B3(N110) & B4(N110) & B4(N330) & B4(N660) \\
\hline $\begin{array}{c}\mathrm{Ea} \\
(\mathrm{kJ} / \mathrm{mol})\end{array}$ & 0.35 & 0.36 & 0.36 & 0.36 & 0.33 & 0.35 & 0.33 \\
\hline
\end{tabular}

Table VII. Influence of the feed temperature on separation factor of the composite membrane

\begin{tabular}{ccccc}
\hline & $30^{\circ} \mathrm{C}$ & $40^{\circ} \mathrm{C}$ & $50{ }^{\circ} \mathrm{C}$ & $60^{\circ} \mathrm{C}$ \\
\hline $\mathrm{PDMS}$ & 9.0 & 9.1 & 9.0 & 8.7 \\
$\mathrm{~B} 1_{(\mathrm{N} 110)}$ & 8.9 & 9.0 & 8.9 & 8.7 \\
$\mathrm{~B} 2_{(\mathrm{N} 110)}$ & 9.0 & 9.0 & 8.7 & 8.8 \\
$\mathrm{~B} 3_{(\mathrm{N} 110)}$ & 9.0 & 9.1 & 9.1 & 9.0 \\
$\mathrm{~B} 4_{(\mathrm{N} 110)}$ & 8.9 & 9.0 & 8.9 & 8.9 \\
$\mathrm{~B} 4_{(\mathrm{N} 330)}$ & 8.9 & 8.9 & 8.6 & 8.6 \\
$\mathrm{~B} 4_{(\mathrm{N} 660)}$ & 8.7 & 8.8 & 8.8 & 8.6 \\
\hline
\end{tabular}

\section{CONCLUSION}

Inclusion of carbon black into PDMS membrane generated addition pathway for the diffusion of permeates, which increased the flux without reducing the selectivity. The treatment of the surface of carbon black played an important role for the increase of flux. The poorer the affinity between carbon black and PDMS matrix, the more the micro-voids occurred, and the greater the flux could be achieved.

Acknowledgment. It is a pleasure to acknowledge the financial support provided by the National Science Foundation of China Grant No. 50073003.

\section{REFERENCES}

1. M. H. V. Mulder and C. A. Smolders, Process. Biochem., 21, 35 (1986)

2. H. Strathmann and W. Gudernatsch, in "Extractive Bioconversions," B. Mattiasson Ed., New York: Marcel Dekker, 1991.

3. Y. Mori and T. Inaba, Biotechnol. Bioeng., 36, 849 (1990).

4. P. Christen, M. Minier, and H. Renon, Biotechnol. Bioeng., 36, 116 (1990).

5. C. W. Cho and S. T. Hwang, J. Membr. Sci., 57, 21 (1991).

6. P. J. Hickey, F. P. Juricic, and C. S. Slater, Sep. Sci. Technol., 27, 843 (1992).

7. Y. Shabtai and C. Mandel, Appl. Microbiol. Biotechnol., 40, 470 (1993).

8. W. Zhang, X. J. Yu, and Q. A. Yuan, Biotechnol. Tech., 9, 299 (1995).
9. Y. M. Lee, D. Bourgeois, and G. Belfort, J. Membr. Sci., 44, 161 (1989).

10. T. Ikegami, H. Yanagishita, D. Kimamoto, K. Haraya, T. Nakane, H. Matsuda, N. Koura, and T. Sano, Biotechnol. Tech., 11, 921 (1997).

11. K. Kargupta, S. Datta, and S. K. Sanyal, Biochem. Eng. J., 1, 31 (1998).

12. D. J. O'Brien, L. H. Roth, and A. J. McAloon, J. Membr. Sci., 166, 105 (2000).

13. M. Di Luccio, C. P. Borges, and T. L. M. Alves, Desalination, 147, 161 (2002).

14. D. J. O'Brien, G. E. Senske, M. J. Kurantz, and J. C. Craig, Bioresour. Technol., 92, 15 (2004).

15. C. W. Cho and S. T. Hwang, J. Membr. Sci., 57, 21 (1991).

16. S. F. Afshar and D. F. Rudd, Biotechnol. Bioeng., 22, 677 (1980).

17. M. Muller and M. N. Pons, J. Chem. Technol. Biotechnol., 52, 343 (1991).

18. W. J. Groot, M. R. Kraayenbrink, R. H. Waldram, R. G. J. M. van der Lans, and K. C. H. A. M. Luyben, Bioprocess. Biosyst. Eng., 8, 99 (1992).

19. H. J. C. te Hennepe, D. Bargenman, M. H. V. Mulder, and C. A. Smolders, J. Membr. Sci., 35, 39 (1987).

20. I. F. J. Vankelecom, D. Depre, S. D. Beukelaer, and J. B. Uytterhoeven, J. Phys. Chem., 99, 13193 (1995).

21. C. S. Slater, P. J. Hickey, and F. P. Juricic, Sep. Sci. Technol., 25, 1063 (1990).

22. S. Takegami, H. Yamada, and S. Tsujii, J. Membr. Sci., 75, 93 (1992).

23. D. R. Paul and D. R. Kemp, J. Polym. Sci., 41, 79 (1973).

24. C. Bartels-Caspers, E. Tusel-Langer, and R. N. Lichtenthaler, J. Membr. Sci., 70, 75 (1992).

25. B. Adnadjevic, J. Jovanovic, and S. Gajinov, J. Membr. Sci., 136, 173 (1997).

26. M. L. Studebaker, Rubber Chem. Technol., 48, 420 (1975).

27. J. B. Donnet, Carbon, 20, 266 (1982).

28. B. Y. Li, "Handbook of Production and Application of Carbon black," Chemical Industry Press, Beijing, 2000.

29. A. Duggal and E. V. Thompson, J. Membr. Sci., 27, 13 (1986).

30. S. P. Shi, Z. J. Du, and H. Q. Li, Polym. J., 37, 925 (2005).

31. P. J. Flory, "Principle of Polymer Chemistry," Cornell University Press, New York, 1953.

32. M. Kakudo and N. Kasai, "X-ray Diffraction by Polymers," Tokyo: Elsevier Publishing Co. 1972.

33. S. Mandal and V. G. Pangarkar, J. Membr. Sci., 201, 175 (2002). 